\title{
Semifluorinated PMMA / PSFMA diblock copolymers with multiple phase separation
}

\author{
D. Jehnichen ${ }^{1,{ }^{*}}$, D. Pospiech ${ }^{1}$, P. Friedel ${ }^{1}$, S.S. Funari ${ }^{2}$ \\ ${ }^{1}$ Leibniz Institute of Polymer Research Dresden, Hohe Str. 6, D-01069 Dresden, Germany \\ ${ }^{2}$ HASYLAB at DESY Hamburg, Notkestr. 85, D-22603 Hamburg, Germany \\ *Contact author; e-mail: djeh@ipfdd.de.
}

Keywords: block copolymers, phase separation, synchrotron X-ray diffraction

\begin{abstract}
Semifluorinated building blocks, i.e. alkyl groups covalently linked to perfluoroalkyl groups with general structure $-\left(\mathrm{CH}_{2}\right)_{\mathrm{n}}-\left(\mathrm{CF}_{2}\right)_{\mathrm{m}^{-}}$are well-known to generate strong microphase separation (driven by a large interaction parameter). If attached as substituents to polymer main chains, self-organization of the side chains induces strong structure formation and form periodic nanostructures in which the side chains are arranged regularly in layers with defined d-spacing. In this work, a semifluorinated poly(perfluoroalkyl methacrylate) block (PSFMA) was linked to a poly(methyl methacrylate) (PMMA) block. Thus, a second type of phase separation caused by demixing of the two blocks (block copolymer phase separation as in PPMA / PMMA diblock copolymers) was found. Temperature-dependent, combined WAXS and SAXS are the ideal methods to investigate both, phase separation of the block copolymers and simultaneously phase separation between main chains and the $-\left(\mathrm{CH}_{2}\right)_{2}-\left(\mathrm{CF}_{2}\right)_{8}-\mathrm{F}$ side chains. Temperature-dependent SAXS/WAXS experiments (heating/ cooling cycles up to $200{ }^{\circ} \mathrm{C}$ ) were performed, which proved the occurrence of block copolymer phase separation with lamellae spacings between $11-17 \mathrm{~nm}$, as well as the formation of semifluorinated layers with d-spacings of $3.1 \mathrm{~nm}$ and a distinct thermal behaviour.
\end{abstract}

\section{Introduction}

Semifluorinated (SF) side chain polymers show a specific microphase separation between polymer backbone and SF side chains, forming an ordered structure. This structure can be best characterized as layer structure in which the backbones and layers of SF side chains alternate. Former experiments examined in detail the behaviour of different polymers with $-\mathrm{O}-\left(\mathrm{CH}_{2}\right)_{10}-\left(\mathrm{CF}_{2}\right)_{10}-\mathrm{F}$ side chains [1a-d]. A combination of different scattering methods and thermal treatments yielded in understanding the special side chain structure (interdigitation and tilt) [2a-b]. The results gave general conclusions about the influence of the backbone flexibility on the self-organization of these SF polymers. Incorporation of $-\mathrm{O}-\left(\mathrm{CH}_{2}\right)_{10}-\left(\mathrm{CF}_{2}\right)_{10}-\mathrm{F}$ side chains lead in all types of polymer backbones used (aromatic and aliphatic polyesters, polysulfones, polypropylene copolymers) to distinguished phase separation with comparable layer structures (reflected by similar d-spacings) [3a-b]. This special structure gave always rise to unusually low surface free energies due to the formation of the 
same structure in the top surface layer. The temperature behaviour of such structures (transition into disordered state) is a crucial point for further application and therefore, combined TWAXS/T-SAXS basic measurements are of great interest.

On the other hand, broad interests focused on microphase separation of block copolymers (BCP). These materials have a big application potential in all fields of nanoscience and -technology due to their periodic morphological structures. Low disperse diblock copolymers based on polymethacrylates, in particular PPMA/PMMA ( $P$ : pentyl) were examined by a combination of methods in former projects [4a-b]. The phase separation in bulk as well as thin films depended on the temperature and molecular parameters. The expectation of strong phase separation (raised by the high Flory-Huggins interaction parameter) in PPMA/PMMA BCP could be confirmed in all BCP. Moreover, the T-SAXS results allowed the assignment of morphology (lamellar, cylindrical), which generated in as-synthesized powder samples after thermal treatment $[4 b-4 c]$.

Here, we report structural investigations of diblock copolymers having a PMMA block connected to a SF methacrylate block. The chemical structures are outlined in figure 1 and scheme 1. Considering the different driving forces a multiple phase separation with mostly layered structures can be expected. Additionally, influences due to different molar masses will occur.
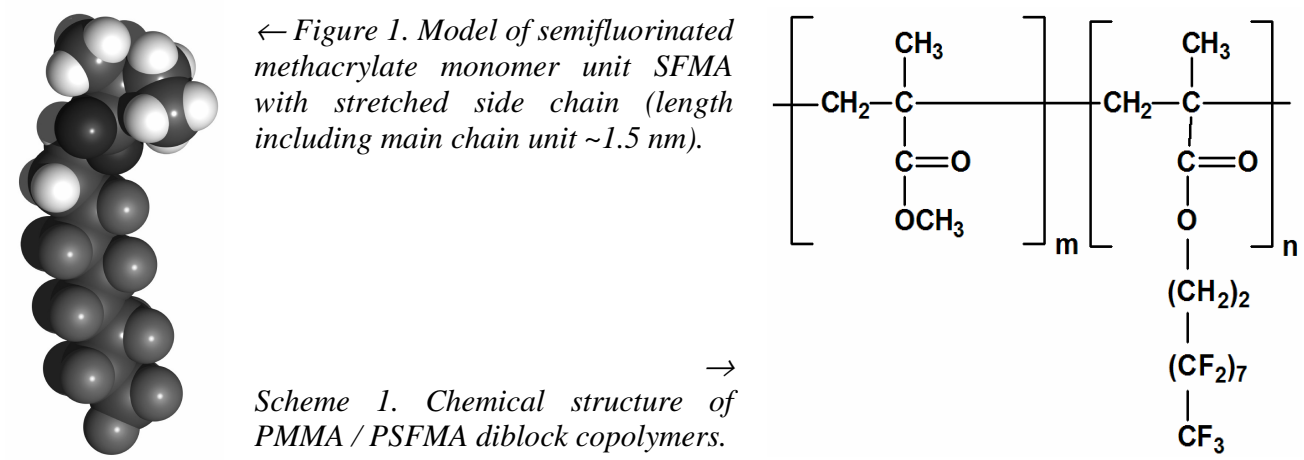

\section{Experimental}

Synthesis: PMMA / PSFMA diblock copolymers and the respective homopolymers were synthesized via sequential living anionic polymerization according to [4a], yielding $80 \%$ syndiotactic products. Molar mass determination was executed by SEC yielding values relative to narrow distributed PMMA standards. Compositions of BCP were obtained from ${ }^{1}$ H NMR spectra. Sample characteristics are given in table 1. Samples were annealed at $140{ }^{\circ} \mathrm{C}$ for 2 days before X-ray experiments.

IMAXS / WAXS: Scattering experiments at room temperature were carried out at diffractometer XRD T/T (GE Inspection Technologies Ahrensburg) in step-scan mode with $\Delta 2 \Theta=0.05^{\circ}$ and $t=20 \mathrm{~s}\left(\mathrm{Cu} \mathrm{K}_{\alpha}\right.$ radiation).

$T$-SAXS / T-WAXS: Combined temperature-dependent small- and wide-angle X-ray scattering was executed with $\lambda=0.15 \mathrm{~nm}$ at the Soft Condensed Matter Beamline A2 (HASYLAB at DESY Hamburg) applying linear detectors. Oven experiments in a typical temperature range 
of $30 \ldots 200{ }^{\circ} \mathrm{C}$ proceeded by heating/cooling rates of $3 \mathrm{~K} / \mathrm{min}$ or by fast cooling and $60 \mathrm{~s}$ duration time per frame and $15 \mathrm{~s}$ accumulation time.

DSC: DSC measurements were performed by means of DSC Q 100 (TA Instruments) with $2 \mathrm{~K} / \mathrm{min}$ heating/cooling/heating cycle. The glass transitions of the PSFMA phase were obtained using modulation experiments and construction of solid and liquid lines.

Table 1. Samples and parameters of analysis.

\begin{tabular}{|c|c|c|c|}
\hline $\begin{array}{c}\text { Sample } \\
\text { name }\end{array}$ & $\begin{array}{c}\text { PMMA / PSFMA } \\
\text { composition } \\
(\mathrm{mol} / \mathrm{mol})\end{array}$ & $\begin{array}{c}\text { Molar mass } \\
M_{\mathrm{w}} \\
(\mathrm{g} / \mathrm{mol})\end{array}$ & $\begin{array}{c}\text { Glass transitions } \\
T_{\mathrm{g}, \mathrm{SFMA}} / T_{\mathrm{g}, \mathrm{MMA}} \\
\left({ }^{\circ} \mathrm{C}\right)\end{array}$ \\
\hline PTFE & --- & commercial sample & 126 \\
\hline PMF 50 & $0 / 100$ & not soluble & $68.8 /-$ \\
\hline PMF 106 & $54 / 46$ & 20,000 & $75.0 / 124.9$ \\
\hline PMF 55 & $71 / 29$ & 9,500 & $70.0 / 105.1$ \\
\hline PMF 51 & $88 / 12$ & 7,500 & $-/ 112.8$ \\
\hline PMF 53 & $97 / 3$ & 15,500 & $-/ 123.3$ \\
\hline PMMA & $100 / 0$ & 23,600 & $-/ 125.0$ \\
\hline
\end{tabular}

$T_{\mathrm{g}}$ from second heating run.

\section{Results and discussion}

All PMMA / PSFMA samples were investigated with respect to the morphology caused by SF side chains using IMAXS and WAXS as well as concerning the phase morphology due to diblock structure by SAXS with T-dependent regimes. An overview about the results is given in table 2 .

Table 2. Morphology of phase separation and structure results.

\begin{tabular}{|c|c|c|c|c|c|}
\hline $\begin{array}{c}\text { Sample } \\
\text { name }\end{array}$ & $\begin{array}{c}\text { Separation of } \\
\text { BCP }\end{array}$ & d-value & $\begin{array}{c}\text { Separation of } \\
\text { SF side chains }\end{array}$ & $\begin{array}{c}\text { d- } \\
\text { value } \\
(\mathrm{nm})\end{array}$ & $\begin{array}{c}\text { Side chain order } \\
d_{(100), \text { hex }} \\
(\mathrm{nm})\end{array}$ \\
\hline PTFE & --- & - & -- & - & 0.490 \\
\hline PMF 50 & --- & - & layered & 3.06 & $0.515^{\text {a) }}$ \\
\hline PMF 106 & lamellar & $\sim 45$ & layered & 3.06 & $0.523^{\text {a) }}$ \\
\hline PMF 55 & hcp cylinders & 12.2 & layered & 3.06 & $0.525^{\text {a) }}$ \\
\hline PMF 51 & lamellar & 11.4 & not found & - & $0.533^{\text {a), b) }}$ \\
\hline PMF 53 & lamellar & 16.8 & not found & - & $0.533^{\text {a), b) }}$ \\
\hline PMMA & --- & - & --- & - & - \\
\hline
\end{tabular}

d-values for $1^{\text {st }}$ reflection; hcp - hexagonally close-packed; ${ }^{\text {a) }}$ - pseudo-hexagonal, ${ }^{\text {b) }}$ - broad maximum.

Figure 2 shows the scattering behaviour in intermediate and wide angle range to illustrate the influence of SF side chains. Well visible and depending on the amount, layered arrangement 
of SF side chains (SF sub-phase) with a distance of $\sim 3.1 \mathrm{~nm}\left(1^{\text {st }}\right.$ to $3^{\text {rd }}$ reflection order) was found. The d-value correlates to the doubled length of the SFMA unit (see scheme 1). Additionally, pseudo-crystalline order (pseudo-hexagonal lateral packing) of SF side chains was observed, which are arranged in a slightly greater distance compared to tetrafluoroethylene chains in PTFE homopolymer (figure 2).

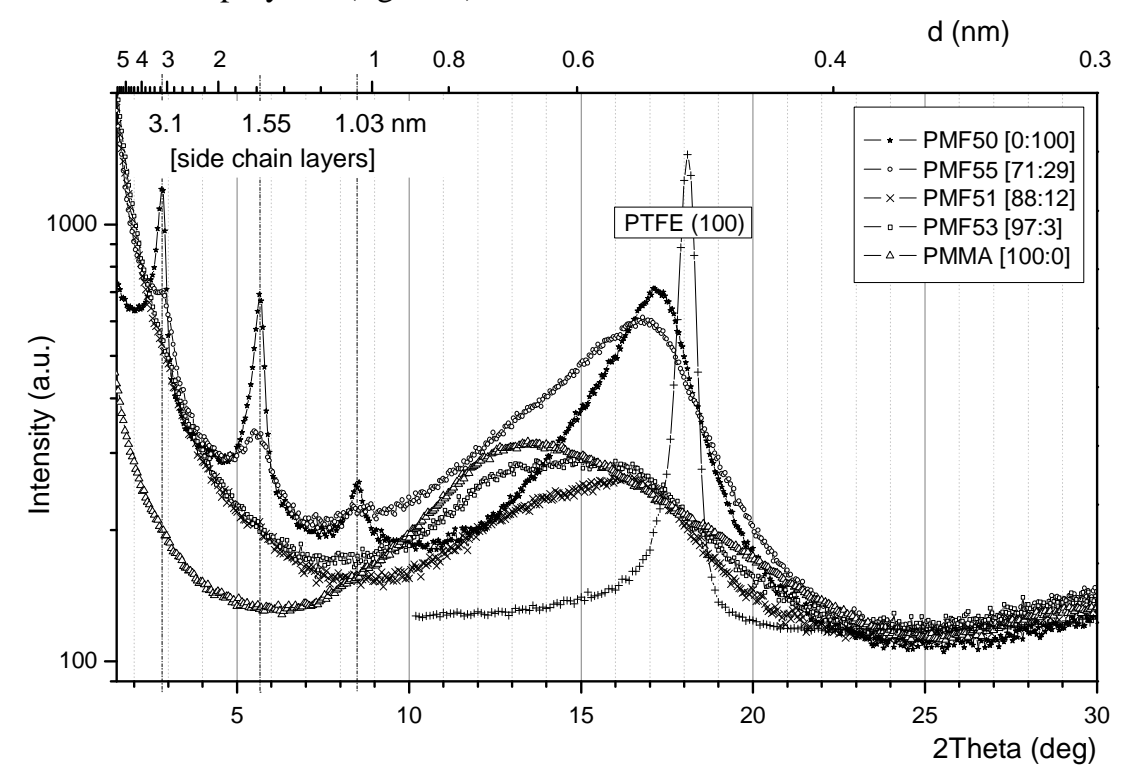

Figure 2. Comparison of IMAXS / WAXS curves of selected samples at room temperature.

T-WAXS experiments with all samples (not pictured here) indicated that the lateral arrangement of SF side chains $(\mathrm{d} \sim 0.515 \ldots 0.533 \mathrm{~nm}$, compare also figure 2$)$ disappears in the glass transition region $\left(T \sim 70 \ldots 75^{\circ} \mathrm{C}\right)$ of the PSFMA phase and is re-generated in the cooling cycle below this $T_{\mathrm{g}}$. The analogue temperature behaviour is reflected in figure 3 .

To give an impression of typical T-SAXS patterns, figure 3 shows as example the contour plot of sample PMF 106. In the displayed d-range the $1^{\text {st }}$ reflection of the side chain layers (upper black line) at $\sim 3.1 \mathrm{~nm}$ at temperatures below $T_{\mathrm{g}}$ (grey lines) is visible. Besides, higher order reflections $\left(2^{\text {nd }}\right.$ to $\left.4^{\text {th }}\right)$ of the lamellar structure of the block copolymer phase separation at 22.5, 15.0, and $11.3 \mathrm{~nm}$, respectively, weakly appear (lower black lines). The latter ones completed by the $1^{\text {st }}$ order reflection of the lamellar structure (with $d_{100} \sim 45 \mathrm{~nm}$ ) caused by BCP phase separation are depicted in figure 4 . The d-values of samples with higher molar mass (PMF 106 as example) depend on $M_{\mathrm{w}}$ as described by the theories of weak and strong segregation limit (WSL, SSL) for symmetric diblock copolymers [5a-b]. Here, the amount of SF side chain plays only a scarce role. The phase separation in samples with lower $M_{\mathrm{w}}$ reflects rather the more complicated phase behaviour of triblock copolymers as that of diblock copolymers. Beside lamellar morphologies also hexagonal cylinder morphologies were detected in a typical composition range (compare table 2), and further lamellar structures for high asymmetric compositions. Obviously, the additional influence of SF side chains gives rise to this behaviour. Investigations in a broader compositional range of $\mathrm{BCP}$ with not too high $M_{\mathrm{w}}$ will provide more details of the constitutive role of the SF side chains. 


\section{Temperature $\left({ }^{\circ} \mathrm{C}\right)$}

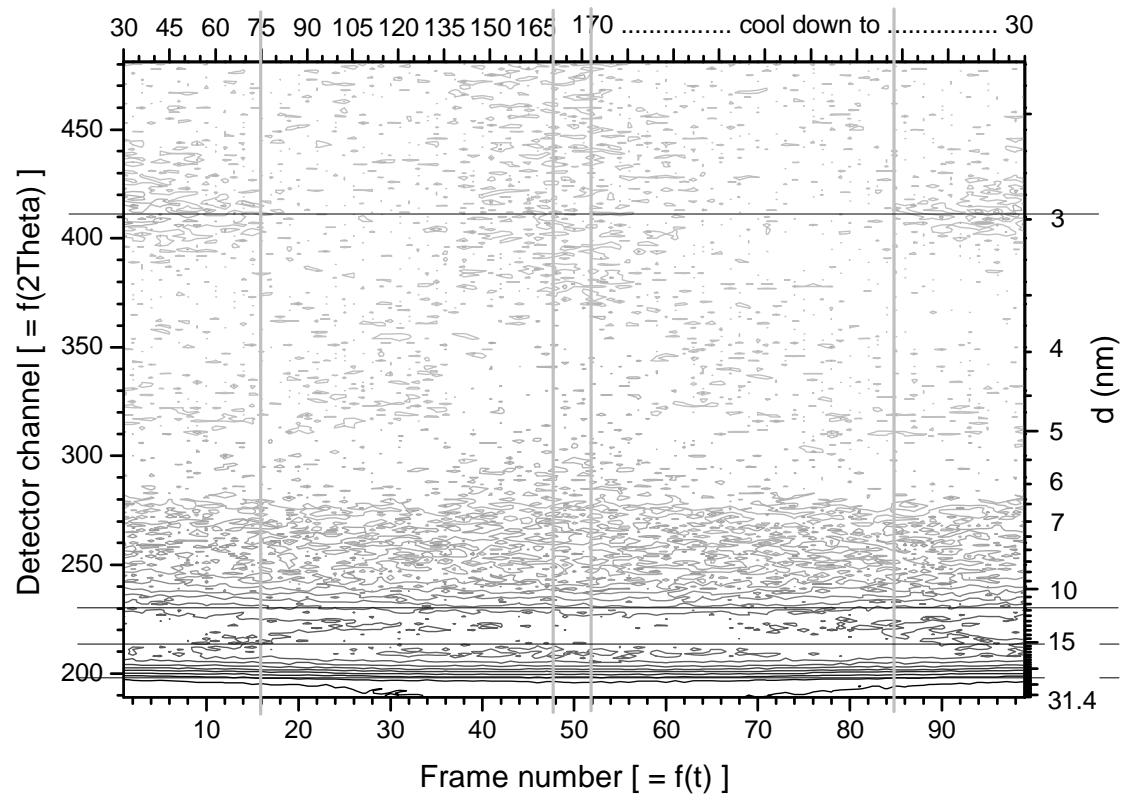

Figure 3. T-SAXS - Contour plot of sample PMF 106 (heating/cooling run, intensity isolines as log(I)greyscale: low [white] $\rightarrow$ high [black]).

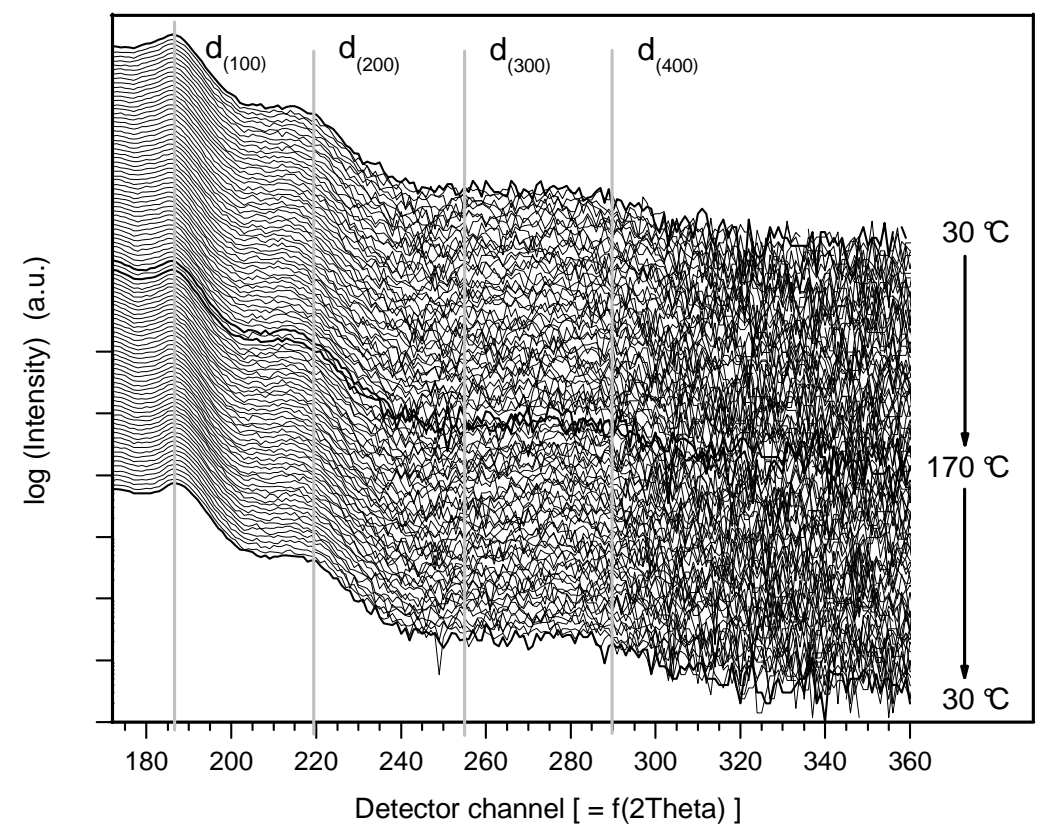

Figure 4. T-SAXS - Waterfall plot of sample PMF 106 (heating/cooling run, zoomed detector channel area in comparison to figure 3 ). 


\section{Summary and conclusions}

Temperature-dependent, combined WAXS and SAXS are the ideal methods to investigate both, phase separation of block copolymers and simultaneously phase separation between the methacrylate backbones and - $\left(\mathrm{CH}_{2}\right)_{2}-\left(\mathrm{CF}_{2}\right)_{8}-\mathrm{F}$ side chains of PMMA / PSFMA diblock copolymers. X-ray measurements proved the occurrence of block copolymer phase separation with lamellae spacings between $10-20 \mathrm{~nm}$ (for low $M_{\mathrm{w}} \mathrm{BCP}$ ) and $>45 \mathrm{~nm}$ for higher molar mass BCP, as well as the formation of SF layers with d-spacings of $\sim 3.1 \mathrm{~nm}$ and distinct thermal behaviour. The d-values of the SF sub-phase and molecular modelling indicated a head-to-head arrangement of SF side chains without interdigitation and tilt. The phase separation in samples with lower $M_{\mathrm{w}}$ reflects more the complicated phase behaviour of triblock copolymers (lamellar, hexagonal or mixed morphologies) as that of diblock copolymers. Detailed investigations have to be performed to clarify these peculiarities.

\section{References}

1. (a) Friedel, P., Pospiech, D., Jehnichen, D., Bergmann, J. \& Ober, C.K., 2000, J. Polym. Sci., Part B: Polym. Phys., 38, 1617. (b) Gottwald, A., Pospiech, D., Jehnichen, D., Häußler, L., Friedel, P., Pionteck, J., Stamm, M. \& Floudas, G., 2002, Macromol. Chem. Phys., 203, 5-6, 854. (c) Pospiech, D., Komber, H., Voigt, D., Jehnichen, D., Häußler, L., Gottwald, A., Eckstein, K., Baier, A. \& Grundke, K., 2003, Macromol. Symp., 199, 173. (d) Pospiech, D., Jehnichen, D., Gottwald, A., Häußler, L., Scheler, U., Friedel, P., Kollig, W., Ober, C.K., Li, X., Hexemer, A., Kramer, E.J. \& Fischer, D.A., 2001, Polym. Mat.: Sci. \& Eng., 84, 314.

2. (a) Jehnichen, D., Pospiech, D., Häußler, L., Friedel, P., Gottwald, A. \& Kummer, S., 2004, Mater. Sci. Forum, 443-444, 223. (b) Jehnichen, D., Pospiech, D., Häußler, L., Friedel, P., Funari, S.S. Tsuwi, J. \& Kremer, F., 2007, Z. Kristallogr. Suppl., 26, 605.

3. (a) Pospiech, D., Häußler, L., Eckstein, K., Komber, H., Voigt, D., Jehnichen, D., Friedel, P., Gottwald, A., Kollig, W. \& Kricheldorf, H.R., 2001, High Perform. Polym. 13, 275. (b) Tsuwi, J., Hartmann, L., Kremer, F., Pospiech, D., Jehnichen, D. \& Häußler, L., 2006, Polymer 47, 7189.

4. (a) Keska, R., Pospiech, D., Eckstein, K., Jehnichen, D., Ptacek, S., Häußler, L., Friedel, P., Janke, A. \& Voit, B., 2006, JNPN, 2, 43. (b) Jehnichen, D., Pospiech, D., Keska, R., Ptacek, S., Janke, A., Funari, S.S., Timmann, A. \& Papadakis, C.M., 2008, JNPN, 4, 119. (c) Jehnichen, D., Pospiech, D., Ptacek, S., Eckstein, K., Friedel, P., Janke, A. \& Papadakis, C.M., 2009, Z. Kristallogr. Suppl. 30, 485.

5. (a) Matsen, M.W. \& Bates, F.S., 1996, Macromolecules, 29, 1091. (b) Melenkevitz, J. \& Muthukumar, M., 1991, Macromolecules, 24, 4199.

Acknowledgements. We thank all colleagues of IPF who contributed to synthesis and characterization of the BCP, especially Mrs. K. Eckstein for anionic polymerization and Mrs. L. Häußler for DSC measurements. We gratefully acknowledge financial support by and participation in EU NoE "NANOFUN-POLY" and by the German Science Foundation. 